\title{
CAPACITAÇÕES PERECÍVEIS DO TRABALHADOR: A BUSCA DE SABERES COMPORTAMENTAIS E TÉCNICOS NO NOVO CAPITALISMO
}

\author{
MAURÍcio dos SANTOS FERREIRA*
}

\begin{abstract}
RESUMO: Este artigo problematiza as estratégias pelas quais a atualização permanente de saberes se impôs como imprescindível ao perfil profissional contemporâneo. Para tanto, opero com os conceitos foucaultianos de discurso, cuidados de si e tecnologias do eu, bem como trabalho imaterial, de Lazzarato e Negri - articulados a uma crítica ao capital humano -, a fim de analisar o caderno Empregos \& Oportunidades do jornal Zero Hora. Centrando-me nas exigências comportamentais e técnicas, destaco algumas implicações: o autoconhecimento torna-se a resposta à trivialidade do trabalho, orientando o sujeito a estabelecer relações superficiais consigo e com o outro; a busca por conhecimento técnico gera contingentes de trabalhadores capacitados que se mantêm em defasagem; a inovação faz-se "dobradiça" entre o mercado e a exigência de novos saberes. Hoje, a condição perecível das capacitações dá o tom à formação do trabalhador.
\end{abstract}

Palavras-chave: Capacitação. Novo capitalismo. Perfil profissional.

\section{Perishable WORKer training: THE SEARCH FOR BEHAVIORAL AND TECHNICAL KNOWLEDGE IN THE NEW CAPITALISM}

ABSTRACT: This paper problematizes the strategies through which the permanent updating of knowledge has been imposed as indispensable to the contemporary professional profile. In order to do that, I have worked with the Foucauldian concepts of discourse, care of the self and technologies of the self, as well as Lazzarato and Negri's concept of immaterial work - articulated with a criticism of human capital - to analyze the supplement called Jobs \& Opportunities of Zero Hora newspaper. Focused on behavioral and technical requirements, I have highlighted some implications: self-knowledge has become the answer to work triviality, leading the subjects to establish superficial relationships with themselves and the others; the search

Curso de Licenciatura em Pedagogia da Universidade do Vale do Rio dos Sinos (Unisinos). Porto Alegre (RS) - Brasil.

Contato com o autor: <mauricioferreira79@hotmail.com> 
for technical knowledge has generated contingents of skilled workers that lag behind; innovation has become a "hinge" between the market and the requirement for new knowledge. Nowadays, the perishable situation of worker training dominates worker learning.

Key words: Worker training. New capitalism. Professional profile.

\title{
LES FORMATIONS PÉRISSABLES DU TRAVAILLEUR: \\ LA RECHERCHE DE SAVOIRS COMPORTAMENTAUX ET TECHNIQUES DANS LE NOUVEAU CAPITALISME
}

\begin{abstract}
RÉSUMÉ: Cet article discute les stratégies par lesquelles la mise à jour permanente de savoirs s'est imposée comme indispendable au profil professionnel contemporain. Pour cela, j'utilise les concepts foucaldien du discours, souci de soi et techniques de soi, ainsi que le travail immatériel, de Lazzarato et de Negri - articulés à une critique au capital humain -, afin d'analyser le cahier Emplois et Occasions du journal Zero Hora. En me centrant dans les exigences comportamentales et techniques, je dégage quelques implications: la connaissance de soi devient la réponse à la futilité du travail, en guidant le sujet à établir des relations superficielles avec soi-même et avec l'autre; la recherche de la connaissance technique produit des contingents de travailleurs capables qui se maintiennent en décalage; l'innovation se fait charnière entre le marché et l'exigence de nouveaux savoirs. Aujourd'hui, la condition périssable des qualifications joue le ton à la formation du travailleur.
\end{abstract}

Mots-clés: Formation. Nouveau capitalisme. Profil professionnel.

\section{Introdução}

$\mathrm{E}$ ste trabalho é um recorte da pesquisa que realizei em 2009 para a dissertação de mestrado em Educação e tem como objetivo compreender e problematizar as estratégias pelas quais a constante atualização de saberes se impôs como imprescindível ao perfil profissional desejado pelo mercado de trabalho contemporâneo, que busca sujeitos responsáveis por seus projetos de carreira, flexíveis e competitivos. A intensa ênfase no imperativo desse aperfeiçoamento contínuo em nossa sociedade levou Richard Sennett (2006) a caracterizá-la como sociedade das capacitações. Segundo esse autor, tais capacitações têm sido compreendidas como "[...] a capacidade de fazer algo novo, em vez de depender do que já se havia aprendido" (p. 93-94). Concebê-las dessa maneira é colocar-se na mesma ordem discursiva em que se encontra a fala de um executivo estadunidense dirigida a estudantes de engenharia:

Na sua carreira, o conhecimento é como um litro de leite. Ele tem um prazo de validade impresso na embalagem. O prazo de validade de um diploma universitário é de menos de dois anos. Portanto, se você não substituir tudo o que sabe a cada três anos, sua carreira irá deteriorar-se, exatamente como aquele litro de leite. (DOM apud MEISTER, 1999, p. 9) 
Em um ambiente de características fluidas, o processo de formar trabalhadores para essa realidade precisa constituir-se de discursos que não mais se refiram ao "emprego para toda vida" (NARDI, 2006). Assim, o que conta como válido é um punhado renovável de experiências e conhecimentos que sirvam enquanto novas mudanças não surjam. É imprescindível renovar-se antes que seu "prazo" vença. Tal imposição às biografias profissionais torna-se possível a partir de um contexto de mudanças nos modos de produção capitalista.

Atravessado por tais problematizações e movendo-me no campo que tem sido reconhecido como estudos foucaultianos, realizei a pesquisa já mencionada, cujo material de análise foram as edições de 2008 do caderno dominical Empregos \& Oportunidades do jornal Zero Hora. A escolha desse artefato deu-se em razão de sua ampla circulação no estado do Rio Grande do Sul e por seu conteúdo apresentar reportagens contendo conceitos, dicas, testes de habilidades que posicionam o leitor na sociedade. Ao pretender informar (e ensinar) a respeito de como se tornar um profissional aceito pelo novo capitalismo, essa mídia impressa fornece elementos que contribuem para a produção de subjetividades flexíveis no mundo do trabalho.

Definida a problemática, operei com o conceito de discurso em Michel Foucault (2007a, p. 55), para quem os discursos são,

[...] Práticas que formam sistematicamente os objetos de que falam. Certamente os discursos são feitos de signos; mas o que fazem é mais que utilizar esses signos para designar coisas. É esse mais que os torna irredutíveis à língua e ao ato da fala. E esse "mais" que é preciso fazer aparecer e que é preciso descrever.

A partir dessa teorização, foi possível criar um percurso metodológico que permitisse organizar os dados empíricos de forma a produzir outros sentidos à "realidade competitiva", da qual emerge o tipo de trabalhador requerido pelo mercado. Ao fazê-lo, outros temas surgiram que não necessariamente aqueles anunciados nas manchetes das reportagens. Importante ressaltar que não buscava a intenção dos autores dos textos, nem algum tipo de evidência verídica ou sentidos ocultos; mantinha-me no nível do discurso e em suas conexões com o governamento ${ }^{1}$ da população.

Além da análise do discurso como ferramenta teórico-metodológica central, destaco os conceitos de capital humano e trabalho imaterial com os quais operei na construção da analítica investigativa e que passo a apresentar, minimamente, nesta introdução. Foucault (2007d, p. 269), em sua análise sobre a Teoria do Capital Humano, questiona: "O que quer dizer formar capital humano, formar, portanto, essa espécie de idoneidade-máquina que vai produzir rendas ou, enfim, que vai ser remunerada com uma renda? Quer dizer, certamente, fazer o que se chama investimentos educacionais". 
Segundo essa perspectiva, os "investimentos educacionais" abrangem um espectro mais amplo, ultrapassando o que está implicado nas aprendizagens escolares ou profissionais. Trata-se de pensar na vida dos sujeitos desde o berço, investindo horas na constituição de um capital, inseparável daquele que o possui, que dê à criança condições para adaptar-se futuramente. Desde Adam Smith, ${ }^{2}$ até o século XX, o alvo da economia era os mecanismos de produção, os mecanismos de troca e as práticas de consumo e suas interferências em um contexto social. A partir da Escola de Chicago, o objeto de análise econômica torna-se a natureza humana, bem como as consequências da assimilação de recursos escassos para fins alternativos. O que está em jogo, portanto, é o comportamento humano. Não se trata de analisar processos e sim uma atividade. O trabalho passa a ser uma conduta econômica e como tal interessa saber "[...] como o trabalhador utiliza os recursos de que dispõe." (FOUCAULT, 2007d, p. 261). Diante disso, os neoliberais apresentam o trabalhador não como um sujeito passivo ou como aquele que, simplesmente, vende sua força de trabalho, mas sim como um sujeito economicamente ativo, portador de um $\mathrm{ca}$ pital humano.

Esses sujeitos, ao planejarem suas carreiras, levando em conta o bem-estar, agem como consumidores que escolhem "livremente" com o que e onde trabalhar. Para Gary Becker (apud FOUCAULT, op. cit., p. 265), "o consumo deve ser considerado como uma atividade de empresa pela qual o indivíduo, precisamente sobre a base de um capital determinado do qual dispõe, produzirá algo que vai ser a sua própria satisfação". Em outras palavras, o Homo æconomicus neoliberal move-se, ao consumir, mais pela competição do que pela simples fruição de coisas. Nessa racionalidade todos seríamos produtores ao consumir, ou seja, empresas em funcionamento. Com isso, o trabalho torna-se imaterial (LAZZARATO; NEGRI, 2001) por tratar-se da satisfação de desejos e afetos. No entanto, não significa que não haja uma mercadoria material, mas o que é valorizado ao produzir ou adquirir algo é o sentido vinculado a esse produto.

O trabalho imaterial produz acima de tudo uma relação social (uma relação de inovação, de produção, de consumo) e somente na presença desta reprodução a sua atividade tem um valor econômico. Esta atividade mostra imediatamente aquilo que a produção material "escondia" - vale dizer que o trabalho não produz somente mercadorias, mas acima de tudo a relação de capital. (LAZZARATO, 2001, p. 46)

Lazzarato (2006, p. 100) complementa essa questão ao escrever que "consumir não se reduz mais a comprar e a 'destruir' um serviço ou um produto, como ensinava a economia política e sua crítica, mas significa, sobretudo, pertencer a um mundo, aderir a um universo". São vastas as implicações dessa organização do capital à educação. Entretanto, volto-me, aqui, somente às capacitações que jovens e adultos fazem para se manterem competitivos. 
Mapeadas as minhas problematizações e definidas as lentes conceituais com as quais olhei para as capacitações dos trabalhadores contemporâneos, passamos, agora, a leitura interessada que fiz dos excertos do jornal Zero Hora, organizada em duas seções: Em busca da diferença, na qual destaco o imperativo do desenvolvimento constante de saberes comportamentais, e Qualifique-se e apareça, onde problematizo a articulação entre conhecimentos técnicos, mercado e inovação.

\section{"Em busca da diferença"3: as capacitações que ensinam sobre si e o outro}

O diferencial é o comportamento. Pelo menos é isso que lemos e ouvimos quando se trata de perfil profissional. A preocupação com a atitude não elimina, de forma alguma, outros pontos a serem considerados na vida profissional. Muito menos podemos afirmar que o comportamento é elemento novo no mundo do trabalho. Quando Taylor (1990) explicava o que levava os operários a fazerem "cera no trabalho", ou seja, diminuir o ritmo de produção, seus argumentos baseavam-se em duas causas: a primeira, chamada de "indolência natural", correspondia a uma tendência do ser humano a fazer o menor esforço, apesar de admitir que alguns homens possuíam energia e vitalidade extraordinárias. Esses, no entanto, sofriam a influência dos indolentes logo nos primeiros contatos. A segunda causa trata-se da "indolência sistêmica", na qual, de forma consciente, os trabalhadores agiriam morosamente para receberem mais.

Ocorreu um investimento, sem dúvidas, em produzir atitudes mais adequadas à lógica da administração científica. Taylor partia da análise dos sistemas produtivos, tal como os economistas clássicos, para concluir que os comportamentos dos trabalhadores influenciavam o ritmo de produção. Porém, a sua ação não se dava, exatamente, sobre as atitudes, mas sim focava os mecanismos de produção - tempos, movimentos e salários - para combater os comportamentos indesejados. Diferentemente, a nova ordem produtiva coloca a forma como agimos no cálculo das relações capitalistas, conferindo-lhe valor e importância cada vez maiores. Uma primeira abordagem que faço é a respeito da necessidade, reiteradamente apresentada, de o sujeito praticar o autoconhecimento. Conhecer-se é apresentado como etapa fundamental para "abrir portas" no mercado. Anunciam os excertos que:

Para se ter sucesso em qualquer trabalho, é preciso desenvolver o autoconhecimento. Ou seja, responder a perguntas como "o que eu gosto de fazer" e "onde quero chegar". Aflição de entrar no mercado desesperadamente faz como que o jovem não pare para refletir, diz Andréa Abs de Agostinho, diretora da Prax Gestão de Carreiras. (ZERO HORA, 6 abr. 2008, p. 2) 
"Se quiser ser alguém quando crescer é preciso estudar muito", assim os pais nos diziam quando éramos crianças. Entretanto, o autoconhecimento passou a ocupar um espaço até então dominado pelos saberes escolarizados. Se já era da pauta das entrevistas de seleção nas empresas perguntar sobre as experiências e formação do candidato, o autoconhecimento apresenta-se como um elemento novo a ser perscrutado. Penso em duas possibilidades: a primeira, que ao saber de si traria a autoconfiança diante do entrevistador; a segunda, que esse exercício torna evidente os "achados" dessa reflexão. Não bastaria tê-los para si, é necessário narrá-los ao interlocutor, porém, com certo cuidado em razão de que nem tudo pode ser dito em todos os lugares. Também, é preciso fazer-se visto para ser lembrado por suas aptidões potenciais de ordem comportamental.

Avançando na análise, entendo que essa preocupação com a interioridade dos sujeitos não se dá por um avanço do processo humanizador das empresas, mas sim por um refinamento nas estratégias e dispositivos do poder característicos da racionalidade neoliberal em conformidade com as demais formas de governamento da população. Nesse sentido, o autoconhecimento suscita uma discussão que se desdobra em um campo extenso da teorização foucaultiana. Falo da ética. Recorro, assim, a alguns autores, além do próprio filósofo, que me auxiliam a pensar as relações do ser-consigo em um processo de capacitação comportamental. Escreve Veiga-Neto (2003, p. 98) que:

A ética, numa perspectiva foucaultiana, faz parte da moral, ao lado do comportamento de cada um e dos códigos que preceituam o que é correto fazer e pensar e que atribuem valores (positivos e negativos) a diferentes comportamentos, em termos morais. [...] Em outras palavras, a ética como "relação de si para consigo".

Nesse sentido, os comportamentos em geral estão envolvidos com a ética, na medida em que os sujeitos tornam-se juízes de si mesmos, por meio de um complexo processo. No caso específico que analiso, a "relação de si para consigo" ocorre através do autoconhecimento. $\mathrm{O}$ trabalhador e o jovem são incentivados a refletirem sobre seus comportamentos, sendo submetidos aos códigos que são norteadores do novo capitalismo. Nessa ação, haverá características que são aceitas e outras não. Não podemos, ingenuamente, esquecer que existem variados fatores envolvidos que constituem o jogo da produção da subjetividade dos indivíduos. Veiga-Neto (op. cit.), mais uma vez, pontua que a ética (ser-consigo) só entra em movimento na produção do sujeito quando opera, simultaneamente, com os outros dois eixos da ontologia foucaultiana - o ser-saber e o ser-poder - que articulam discursos e formas de conduzir as diversas condutas. Portanto, "[...] o sujeito é um produto, ao mesmo tempo, dos saberes, dos poderes e da ética" (ibid., p. 99).

Esse domínio, o ser-consigo no qual o autoconhecimento está inserido, dá-se com base em determinadas tecnologias, as quais Foucault (1990) denominou de 
"tecnologias do eu", voltadas à transformação de si com o fim de obter felicidade, pureza ou sabedoria. O filósofo remonta à Grécia antiga para ver que a preocupação de si para consigo já estava presente naquela sociedade. Na Contemporaneidade, encontramos essas tecnologias em contextos pedagógicos, terapêuticos e mais recentemente organizacionais, e partem do princípio de que o ser humano necessita decifrar-se, tomar consciência do seu eu, operar sobre sua alma e corpo. Todo investimento que se faz nesse sentido deve ser entendido de forma ampla, perfazendo as sociedades ocidentais e constituindo uma "cultura de si".

Pode-se caracterizar brevemente essa "cultura de si" pelo fato de que a arte da existência - a techne tou biou sob as suas diferentes formas - nela se encontra dominada pelo princípio segundo o qual é preciso "ter cuidado consigo"; é esse princípio do cuidado de si que fundamenta a sua necessidade, comanda o seu desenvolvimento e organiza a sua prática. (FOUCAULT, 2007c, p. 49)

O que, a princípio, poderia levar ao entendimento do individualismo como responsável por uma crescente preocupação pelos "aspectos privados" da existência, é mostrado pelo autor de modo contrário em sua História da sexualidade. Teria sido, sim, o fenômeno da cultura de si que possibilitou a promoção da austeridade sexual e, por conseguinte, de uma disseminação de práticas sociais que levam os sujeitos a tomarem a si próprios como local e objeto de purificação. De acordo com os excertos analisados, a questão comportamental, juntamente com a teorização sobre a cultura de si, sugere que os leitores do jornal deem conta dos detalhes da "arte da existência", tal como podemos observar:

Portanto, o trunfo de quem está de olho no trabalho é conquistar a confiança do entrevistador - antes de tudo, é claro, precisa ter um currículo à altura, demonstrar confiança sem parecer arrogante e saber falar de si próprio. - Significa ter qualidades, experiências e se conhecer - afirma Augusto da Costa, Manpower. (ZERO HORA, 9 mar. 2008, p. 3)

Manter a calma e apontar as suas potencialidades é fundamental, apontam especialistas. [...] - Fale sobre um projeto de sucesso associado ao perfil do cargo descrito - sugere Márcia Testa, diretora regional do Grupo Foco. (Idem, 1 jun. 2008, p. 2)

Tente se conhecer melhor: pense nas situações que você se imagina vivenciando. Por exemplo, se tem facilidade para falar em público ou no relacionamento com pessoas; [...] sonhe sonhos possíveis e trace metas. (Idem, 6 abr. 2008, p. 2)

A respeito dessas operações do indivíduo sobre si mesmo, Larrosa (1994), realiza um estudo sobre as estratégias que circulam pela escola moderna e que mantêm relações intrínsecas com as tecnologias do eu. Sua pesquisa aponta a possibilidade de agrupar essas descrições e interrogações nas quais os alunos são envolvidos em cinco dispositivos: "expressar-se", "narrar-se", "ver-se", "julgar-se" e o "dominar-se". Sem perder de vista a ocorrência de uma operação "idiossincrática do discurso" 
presente no material empírico, exploro os excertos anteriores, seguindo os achados desse pesquisador.

$\mathrm{O}$ "expressar-se" corresponde à necessidade de "tornar visível" aquilo que o sujeito "viu" dentro de si e agora tem que expor, apresentando-se de certa forma aos outros. A linguagem, no sentido amplo, assume um papel importante por ser o meio utilizado por essa estratégia. Essa técnica é recomendada para o momento durante a entrevista de emprego. Quando abordado pelo recrutador, deve-se saber como falar de si. Estão em jogo as questões morais e éticas, pois conforme o que for expresso, socialmente, pode ser interpretado como "arrogante" ou elogiável. Poder contar os projetos em que esteve à frente ou envolvido e seus resultados exige uma interiorização, a fim de levantar dados e valorar os feitos. Os códigos acerca do que deve ou não ser apresentado estão expressos no cargo almejado e naquilo que a empresa busca em termos de perfil. Talvez, na descrição dos fatos, sejam menos significativas as situações do que a forma como o candidato agiu diante dos problemas, uma vez que o potencial aparece como alvo. Seguindo o esquema de Larrosa (op. cit.), nesse momento é acionado o "narrar-se". A tentativa de resgate histórico do eu traz a recordação dos fatos e de si, tornando o sujeito personagem, narrador e ouvinte, à medida que explica os detalhes dos projetos, rotinas e posturas assumidas.

Enquanto esses dois recursos que identifiquei nos fragmentos apresentados orientam o trabalhador durante a entrevista, o "ver-se" fala da preparação do candidato. A estratégia corresponde à tarefa de olhar para seu passado, para suas atitudes e para seu interior, obtendo um desdobramento de si em uma imagem exterior, semelhante a um espelho, onde poderia, agora munido de mais clareza e maturidade, analisar-se através da reflexão. Imaginar-se em situações pouco confortantes e projetar possibilidades de ações que lhe deem mais confiança caracterizariam essa tecnologia do eu. Esse exercício da alma contribui, também, no desafio de traçar objetivos e metas mais plausíveis para a vida do sujeito.

Manter controle dos desejos e das emoções exige do trabalhador decifrar as normas de conduta que o local exige. Deve ponderar suas reações, exortando-se, constantemente, a fim de não se tornar hostil no ambiente de trabalho. O "julgar-se" torna o sujeito autogovernável, que sabe avaliar suas atitudes e pensamentos, a partir de uma matriz moral. Essa estratégia liga-se diretamente à última, que é o "dominar-se", onde as pessoas, depois de julgarem-se, vão tomar atitudes sobre si mesmas. Todos esses cinco dispositivos, ao fim e ao cabo, funcionam relacionados uns com os outros, mas o que é menos evidente é que aparecem como técnicas neutras que não se imiscuem com o "conteúdo" que fazem emergir. Larrosa (1994, p. 65), no entanto, alerta-nos para esse fato ao escrever que: 
O "ver" e o "fazer ver" se correspondem, embora não se identifiquem, com o "falar" e o "fazer falar". A distribuição histórica do que se vê e do que se oculta vai em paralelo com a distribuição do que se diz e do que se cala. O visível vai em paralelo com o dizível. As formas legítimas de olhar se relacionam com as formas legítimas de dizer.

O discurso empresarial conferirá legitimidade àquilo que é visto e dito, determinando as possibilidades da visão e da fala. Todo esse conjunto de estratégias que venho analisando e que assumo como autoconhecimento faz essa conexão entre o que é visto e o que é dito. O trabalhador, ao ser convocado a capacitar o seu olhar para ver a si mesmo, o fará a partir de determinada regras que o permitirão enxergar e, posteriormente, falar o que já estava enunciado, ou seja, ser flexível, resiliente, tolerante a frustrações. Poderíamos resumir a questão deduzindo que o sujeito, ao ver o que supostamente estaria em si, está introjetando ${ }^{4}$ o dito.

Em outro excerto encontramos um ponto novo para a análise do autoconhecimento. Refere-se à importância dedicada às demais pessoas. Em um ambiente profissional, além de conhecer-se, é necessário estar atento às formas de falar, agir, comunicar-se, a fim de obter resultados.

Trabalhe focado na divulgação de resultados que obteve com seu trabalho; entenda o que a empresa espera de você; quando trabalhar em equipe, evite o uso do pronome "eu". Prefira sempre "nós". (ZERO HORA, 15 jun. 2008, p. 1)

Em meio à "turbulência" organizacional, o sujeito deve encontrar formas de integrar-se aos seus colegas para formar equipes, conjugando as vitórias e derrotas sempre na primeira pessoa do plural. Uma vez que o trabalho contemporâneo recebe uma conotação imaterial, é justo que a comunicação assuma um destaque como aptidão do trabalhador. Nas empresas, quem for comunicar precisa estar atento ao seu público-alvo, à linguagem adequada, ao volume e sequência das informações, demonstrando assim que, de algum jeito, está preocupado com os colegas. A esse respeito, Sennett (2005, p. 118) analisa que, "apesar de todo o arquejo psicológico da administração moderna sobre o trabalho de equipe no escritório e na fábrica, é o ethos de trabalho que permanece na superfície da experiência. $\mathrm{O}$ trabalho de equipe é a prática de grupo da superficialidade degradante". E não poderia ser diferente, uma vez que é solicitada a todos nós uma postura de turista ${ }^{5}$ nos empregos e nas relações.

O que vejo nesse excerto é a preocupação com o outro ao tratar as questões comportamentais, seja no compartilhamento de responsabilidades e tarefas, no contato diário dentro do ambiente profissional ou na necessidade de divulgação daquilo que foi realizado. Aparentemente, poderíamos entender que há certo esmaecimento da relação do sujeito consigo mesmo, pois as tarefas e recomendações de como abordar os outros projetam o olhar para o exterior, sobre as pessoas e o contexto. 
Entretanto, vamos encontrar em Foucault (2007c, p. 55-56) uma importante consideração acerca de um conceito utilizado pelos gregos e que amplia, ainda mais, a compreensão do exercício de si para consigo:

O termo epimeleia não designa simplesmente uma preocupação, mas todo um conjunto de ocupações; trata-se de epimeleia quando se fala para designar as atividades do dono de casa, as tarefas do príncipe que vela por seus súditos, os cuidados que se deve ter para com um doente ou para com um ferido, ou ainda as obrigações que se prestam aos deuses ou aos mortos. Igualmente, em relação a si mesmo, a epimeleia implica um labor.

Não se trata somente de uma "preocupação" que os sujeitos teriam consigo. Envolve um conjunto de "ocupações" com a sua alma, com os demais e com as questões sociais e políticas. O cultivo de si somente teria sentido se envolvesse o outro de alguma forma - uma típica prática social. Apesar das provações impostas a si, acompanhadas de "exames de consciência", esse exercício não refletia um processo de culpabilização, mas sim de correção, ajuste da alma para melhor servir e elevar-se, cujo objetivo pode ser resumido em obter o "bem comum”. O contrário seria mera contemplação. ${ }^{6}$

Temos, assim, alguns elementos que nos fazem pensar na cultura de si como uma "resposta" às questões que colocam o sujeito, constantemente, em exercício de autoconhecimento e de modelagem do seu comportamento na comunicação com colegas, no tratamento adequado com pares e superiores. Destaco que a prática grega da epimeleia, segundo Foucault (2007c), exigia tempo para sua efetivação e era nisso que consistia seu maior problema. Na Contemporaneidade, como reivindicar tempo diante de um capitalismo flexível, cujas mudanças de prioridades e pessoas ocorrem a todo instante? Como conhecer-se, cuidar de si, se o que a empresa precisa é agilidade na tomada de decisão e gerenciamento das mudanças? Concluo que os exercícios de autoconhecimento, do ser-consigo, são tecnologias de autogovernamento que produzem uma subjetividade que não busca aprofundamentos. A forma como o sujeito relaciona-se consigo e com o outro o leva a ver-se, expressar-se, narrar-se, julgar-se e dominar-se, como já mencionado, no nível da superficialidade, o suficiente para dar uma resposta imediata à nova situação assim que ela se apresente.

Em razão da alta velocidade das demandas, o "produto" do autoconhecimento passa a ser as respostas à trivialidade e às questões pontuais do trabalho. Qualquer tentativa de "amadurecimento" é logo desviada para outra urgência. Portanto, se o diferencial é conhecer-se e conhecer o outro, isso passa pelo crivo da superficialidade - que não se aprofunda; que não se detém demoradamente -, o que não quer dizer que seja menos insidioso. Encontro em Sennett (2006, p. 118) a síntese desse meu argumento: “a pressão para obter resultados rápidos é demasiado intensa; tal 
como nos testes educacionais, também no trabalho a angústia do tempo leva as pessoas a deslizar na superfície, em vez de mergulhar".

\section{"Qualifique-se e apareça"7: articulações entre mercado, inovação e saberes técnicos}

Enquanto as capacitações comportamentais podem proporcionar aos sujeitos diferenciarem-se dos demais, as capacitações técnicas aparecem, em minhas análises, como uma das condições básicas para alguém existir profissionalmente, caso contrário não terá visibilidade no mundo do trabalho. Entretanto, isso não representa exatamente uma novidade, pois o capitalismo industrial significou a aplicação de conhecimento científico à produção. Corsani $(2003$, p. 26) argumenta que a mudança está "[...] no fato de que o conhecimento é, agora, ao mesmo tempo um recurso e um produto, desincorporado de qualquer recurso e de qualquer produto".

Portanto, o que ocorre no pós-fordismo é a "produção de conhecimentos pelos conhecimentos", que por sua vez não é incorporado nem ao trabalho nem à máquina, circula, independente, e se difunde nos "contextos de produção e de consumo". Conforme Corsani (op. cit.), as novas tecnologias da informação e comunicação (NTIC) potencializam essa produção e circulação do conhecimento. Nesse sentido, argumento que o domínio técnico configura-se no discurso contemporâneo não tanto como conhecimento que encerre em si o seu valor, a exemplo do torneiro mecânico que domina uma técnica e uma operação, mas como uma estratégia de governamento que pretende manter os sujeitos sempre abertos para a captura do acontecimento, das situações aleatórias. Vejamos o que diz o próximo excerto:

- A dica [para se qualificar] é estar sempre se atualizando, principalmente porque os recursos tecnológicos estão impactando em todas as áreas. Hoje, tanto quem exerce um cargo executivo quanto um trabalhador da área de serviços e um garçom devem saber como se trabalha com um palmtop (microcomputador portátil) - afirma Flávio Martins [coordenador das áreas de Relacionamento e Corporativa da Escola Superior de Propaganda e Marketing - ESPM/RS]. (ZERO HORA, 24 fev. 2008, p. 1)

Ingenuamente, poderíamos acreditar que a produção de conhecimento é restrita a um grupo de trabalhadores, cujas atividades estariam, diretamente, ligadas à criação, à arte ou à gestão, cabendo aos demais permanecerem voltados à produção de bens e serviços. Mas existe uma tendência dos outros segmentos do mercado a avançarem na produção de mundos (LAZZARATO, 2006). Do executivo ao garçom, parece que todos precisam se apropriar de ferramentas digitais, pois a velocidade com que são lançadas novas tecnologias torna o conhecimento obsoleto em pouco tempo. Além disso, entendo que o próprio conhecimento sobre os campos de atuação dos 
profissionais está, intrinsecamente, ligado a essas tecnologias, sem as quais, talvez, não se consiga trabalhar. Geralmente, as "soluções de informática" são apresentadas como facilitadoras dos processos de trabalho.

Os "benefícios" propiciados pelas NTIC somente ocorrem na medida em que os trabalhadores qualificam-se, dominam tais tecnologias de seu tempo. Se partirmos da compreensão de que cada sociedade tem seu suporte material, sua maquinaria (SARAIVA, 2006), a informática é, por excelência, o suporte material contemporâneo. Vê-la como simples avanço da ciência ou como evolução (ou revolução) tecnológica é partir de uma neutralidade cientificista e filosófica. Prefiro problematizar a questão como jogos de verdades, em que a visibilidade dos mesmos nos remeterá a outros jogos, com outras regras, novos adversários e outras verdades. Há uma produtividade que precisa ser levada em conta e isso significa que os discursos e os poderes constituem sujeitos, subjetividades, realidades e saberes.

Quando conhecemos algo, estamos nos produzindo e dessa relação não conseguimos fugir. Quanto mais nos apropriamos das tecnologias de nossa época, mais nos subjetivamos de acordo com essas condições, ou seja, "nosso modo de pensamento se constitui no entrelaçamento com as tecnologias disponíveis" (SARAIVA, op. cit., p. 196). A informática é uma resposta a determinado tipo de sociedade (a nossa) e conhecer, dominar os seus recursos faz com que participemos de sua efetivação e alteração.

Enquanto as tecnologias mecânicas repousam sobre a "especialização das máquinas", conforme a função e uso determinados pelo conhecimento incorporado - um torno serve para tornear peças -, as máquinas digitais ligadas em rede não possuem uma função determinada, podem servir para inúmeras coisas que o usuário desejar. "As NTIC constituem, com efeito, uma verdadeira ruptura na história das técnicas, pois se apóiam em uma dissociação entre a máquina (hardware) e seu programa (software). [...] Como metamáquina, o PC em rede é literalmente uma caixa vazia" (CORSANI, 2003, p. 22). O conhecimento não é incorporado à máquina, e o próprio processo de criação de novos conhecimentos é apreendido pela lógica capitalista. Acrescenta Corsani (ibid.) que, nesse contexto, "[...] o trabalho se transforma em criação de usos [...]" por meio dos usos criados. O desempenho das ferramentas digitais está, intimamente, imbricado com as aplicações criativas e inovadoras que os sujeitos, sobretudo quando conectados em rede, fazem de seus recursos, sem as quais essas maquinarias permanecem medíocres.

Sem sombra de dúvida, o computador e todas as tecnologias desenvolvidas a partir do seu princípio de funcionamento tiveram um papel importante nas questões que estou analisando acerca das capacitações exigidas pelo atual perfil profissional desejado. O conhecimento tecnológico (MEISTER, 1999) que o trabalhador deve 
adquirir só faz sentido quando olhamos para o seu entorno, para as condições de possibilidade da própria tecnologia. Tal conhecimento técnico impõe-se aos trabalhadores toda vez que pode propiciar a inovação dos processos e produtos. O domínio das NTIC busca a criação de novas "soluções", o que, de fato, entra em sintonia com as empresas flexíveis que precisam "[...] de indivíduos capazes de aprender novas capacitações, em vez de se aferrarem a antigas competências" (SENNETT, 2006, p. 107-108).

Para encerrar esta seção, trago a tendência de colocar os sujeitos sempre em busca de novas qualificações. Ao ser entrevistado, um aposentado metalúrgico comenta que um bom trabalhador era "aquele que cumpria o horário e respeitava suas obrigações. [...] Hoje, pensa que o bom trabalhador é aquele que está sempre se atualizando" (NARDI, 2006, p. 153). Essa formação continuada também está explícita no jornal Zero Hora:

\begin{abstract}
A velocidade das mudanças no mercado de trabalho exige aperfeiçoamento e atualização mesmo de quem está concluindo a universidade. Mas antes de se decidir por uma pós-graduação, o recém-formado deve tomar algumas providências para evitar futuros arrependimentos, perda de tempo e de dinheiro. [...] A primeira definição deve ser sobre se deseja seguir a carreira acadêmica ou se aperfeiçoar na profissão escolhida. Decisão tomada, o próximo passo é escolher o curso. (10 fev. 2008, p. 3)
\end{abstract}

Quando abordamos a questão da formação profissional, já é lugar comum afirmar que ser graduado não garante emprego a ninguém. $\mathrm{O}$ ritmo acelerado do mercado de trabalho faz com que o conhecimento adquirido durante os anos da faculdade precise ser renovado, se não completamente substituído. Isso exige que os sujeitos comecem a planejar a continuação da formação antes mesmo de encerrar a graduação. No entanto, pouco se comenta a respeito da geração de um contingente de trabalhadores capacitados que estão sempre em "débito" com o mercado. Sennett (2005, p. 105) escreve que "o excesso de qualificação é um sinal da polarização que caracteriza o novo regime". Enquanto o sujeito acreditar que está "devendo" em termos técnicos, buscará sempre mais qualificações a fim de manter-se competitivo.

Uma formação que se faz ao longo da vida, envolvendo aspectos da experiência e do conhecimento, precisa estar ligada a uma "matriz" que direcione os esforços e gere demandas a fim mobilizar a população. A complexidade e a flexibilidade do discurso neoliberal, cujo principal dispositivo de controle é a liberdade, e o maior objetivo é a livre concorrência, conduzem-me a refletir acerca dos conhecimentos e suas funções dentro do campo de ação da racionalidade em questão. Uma competência técnica que permita que os sujeitos liberem-se do que já é sabido e que propicie a efetivação de novos mundos deverá, segundo a minha percepção, ligar-se aos processos de criação e inovação. 
Proponho, portanto, compreender a inovação como "dobradiça", articuladora, entre as demandas do mercado (flexibilidade, curto prazo, criação de mundos) e os conhecimentos que os trabalhadores precisam dominar, pois, na medida em que o mercado precisa de inovações para sustentar-se, surge a necessidade de conhecimentos para criar algo novo. Em termos gerais, as razões que me levaram a pensar na possibilidade da inovação, como dobradiça, estão relacionadas à conclusão a que Cocco, Galvão e Silva (2003, p. 9) chegaram acerca do capitalismo cognitivo: “à medida que as pesquisas sobre a economia cognitiva se desenvolvem, elas encontram cada vez mais as temáticas ligadas à dinâmica da inovação" (grifos meus).

Foucault (2007d, p. 271), em uma das aulas ministradas no Collège de France, em 1979, após apresentar o capital humano como uma produção da escola de Chicago, questionou-se sobre o porquê dessa análise. Sem hesitar, ele próprio responde: "Em efeito, esse tipo de análise permite antes de tudo revisar um pouco uma série de fenômenos identificados já há algum tempo, final do século XIX, e que não se deu exatamente o status necessário. Refiro-me ao problema do progresso técnico e incluo aquilo que Schumpeter chamava de 'inovação'”.

Estamos diante de uma vinculação entre capital humano e a inovação, o que, por sinal, mostra-se muito produtivo para as discussões que tenho proposto neste artigo. Para dar os contornos dessa relação, volto a Foucault (op. cit.) que, por sua vez, retoma Schumpeter. ${ }^{8}$ Ao analisar a baixa ou a correção da margem de lucro, Schumpeter concluiu que isso não se deve somente a um fenômeno imperialista. ${ }^{9}$ Deve-se à inovação, ao descobrimento de novas técnicas, de novas fontes, de novas formas de produzir, de novos mercados e novos recursos de mão de obra. Caberá ao próprio mercado pensar e desenvolver tais inovações tecnológicas, uma vez que é importante para o capitalismo o ajuste da taxa de lucro.

Os neoliberais farão, a esse respeito, a reflexão de que não é possível colocar o problema da inovação, considerado crucial para o crescimento, à mercê do capitalismo para explicar os fenômenos correspondentes. Dizem esses economistas que se há inovação "[...] não é mais do que a renda de certo capital, o capital humano, ou seja, o conjunto dos investimentos que se tem feito no próprio homem" (FOUCALT, 2007d, p. 272). Conclui-se que há a possibilidade de uma política de crescimento voltada para os investimentos no capital humano. A educação ou formação continuada pode ser muito bem entendida como um enunciado para incentivar o crescimento contínuo dessa idoneidade-máquina. De certa forma, vejo essa apropriação do fator inovação como um forte argumento em favor do pós-fordismo, pois o conhecimento (e os afetos) passa a ser o principal fator no sistema produtivo atual. Levando adiante essa discussão, Lazzarato (2003, p. 62) propõe que:

Ao lado da "teoria das riquezas", tal como é concebida pela economia política, é preciso desenvolver uma "teoria dos conhecimentos" baseada na crença e uma teoria das paixões 
baseada no "sentir", fazendo dos conhecimentos e das paixões forças econômicas que explicam a especificidade das economias modernas.

Sejam dos aspectos da crença (conhecimento) ou do sentir (paixões), os saberes considerados válidos serão somente aqueles que possibilitarem aos indivíduos criarem coisas novas, pois enquanto o "novo" no fordismo era algo eventual, hoje o "novo" constitui o próprio capitalismo.

\section{Considerações finais}

Para encerrar, destaco que a problematização apresentada nestas páginas - o autoconhecimento como resposta à trivialidade; a renovação permanente do conhecimento técnico; a inovação como articuladora de demandas de capacitação possibilitou-me tomar o novo perfil profissional como instância de ação de uma pedagogia empreendedora (COSTA, 2009), cujos motes são as constantes defasagens dos saberes e os investimentos que o trabalhador faz em relação a si mesmo. Essa condição perecível das capacitações não significa que sejam menos importantes, pelo contrário, ela dá o tom ao ritmo da atualização que envolve tanto questões comportamentais quanto técnicas. Enfim, a problemática que levanto é que as manifestações de liberdade, autoconhecimento, domínio técnico, flexibilidade, como táticas de poder, presentes nos discursos das novas formas de trabalho e geração de saberes, materializados no caderno Empregos \& Oportunidades do jornal Zero Hora, pouco nos remetem a uma condição que permita contestarmos aquilo no qual nos tornamos: sujeitos flexíveis portadores de um capital humano.

\section{Notas}

1. Veiga-Neto (2002, p. 21) aconselha que se utilize a expressão governamento no lugar da palavra governo, pois esta última nos remete à instituição do Estado. Como Foucault, no decorrer de sua obra, não se refere às ações centralizadas no Estado, mas sim às "ações distribuídas microfisicamente pelo tecido social" e que têm por objetivo conduzir as condutas, "[...] soa bem mais claro falarmos aí em práticas de governamento".

2. Economista escocês (1723-1790).

3. Zero Hora, 16 mar. 2008, p. 1. Como sínteses dos argumentos desenvolvidos, trago, entre aspas, nos títulos, as manchetes ou fragmentos das reportagens do caderno Empregos \& Oportunidades.

4. Estou utilizando o termo "introjeção" em sua acepção mais corrente, sem a conotação dada pela psicanálise.

5. Refiro-me à metáfora que Bauman (1998, p. 114) constrói sobre uma parcela da população que não assume responsabilidades e vínculos com os lugares por onde passa. Diz o sociólogo que "a figura do turista é a epítome dessa evitação".

6. Foucault lembra-nos de que essa prática - epimeleia - sofreu inúmeras alterações ao ser apropriada por diversas culturas e religiões. Gallo (2006) destaca que enquanto o "cuidar de si" grego constituía a base da política (cuidar de si para cuidar do outro), nos tempos imperiais (greco-romano) inverte-se a situação e o mais importante é o "cuidar de si mesmo". 
7. Zero Hora, 24 fev. 2008, p. 1.

8. Joseph Alois Schumpeter (1883-1950). "Por 'inovação tecnológica', Schumpeter entende cinco categorias de fatores: a fabricação de um novo bem; a introdução de um novo método; a conquista de uma nova fonte de matérias-primas; a realização de uma nova organização econômica, tal como o estabelecimento de uma situação de monopólio" (SANDRONI, 1999, p. 318-319).

9. Imperialismo refere-se à necessidade das grandes potências econômicas garantirem mercados e matérias-primas (SANDRONI, 1999).

\section{Referências}

BAUMAN, Z. O mal-estar da pós-modernidade. Rio de Janeiro: Zahar, 1998.

BAUMAN, Z. Modernidade líquida. Rio de Janeiro: Zahar, 2001.

COCCO, G.; GALVÃO, A.P.; SILVA, G. (Org.). Capitalismo cognitivo: trabalho, redes e inovação. Rio de Janeiro: DP\&A, 2003.

COMO eles decidem. Seleção. Zero Hora, Porto Alegre, 9 mar. 2008. Caderno Empregos \& Oportunidades. Brasil, p. 3.

COMO escolher o curso mais adequado. Zero Hora, Porto Alegre, 10 fev. 2008. Caderno Empregos \& Oportunidades. Brasil, p. 3.

CORSANI, A. Elementos de uma ruptura: a hipótese do capitalismo cognitivo. In: COCCO, G.; GALVÃO, A.P.; SILVA, G. (Org.). Capitalismo cognitivo: trabalho, redes e inovação. Rio de Janeiro: DP\&A, 2003. p. 15-32.

COSTA, S.S.G. Governamentalidade neoliberal, teoria do capital humano e empreendedorismo. Educação \& Realidade, Porto Alegre, v. 34, n. 2, p. 171-186, maio/ago. 2009.

EM busca da diferença. Zero Hora, Porto Alegre, 16 mar. 2008. Caderno Empregos \& Oportunidades. Brasil, p. 1.

FOUCAULT, M. Tecnologías del Yo: y otros textos afines. Barcelona: Paidós, 1990.

FOUCAULT, M. A arqueologia do saber. 7. ed. Rio de Janeiro: Forense Universitária, 2007a.

FOUCAULT, M. A ordem do discurso: aula inaugural no Collège de France, pronunciada em 2 de dezembro de 1970. 15. ed. São Paulo: Loyola, $2007 b$.

FOUCAULT, M. História da sexualidade 3: o cuidado de si. 9. ed. Rio de Janeiro: Graal, 2007c.

FOUCAULT, M. Nacimiento de la biopolitica; curso en el Collège de France: 1978-1979. Buenos Aires: Fondo de Cultura Econômica, 2007d. 
GALLO, S. Cuidar de si e cuidar do outro: implicações éticas para a educação dos últimos escritos de Foucault. In: KOHAN, W.O.; GONDRA, J.G. (Org.). Foucault 80 anos. Belo Horizonte: Autêntica, 2006. p. 177-189.

LARROSA, J. Tecnologias do eu e educação. In: SILVA, T.T. (Org.). O sujeito da educação: estudos foucaultianos. 4. ed. Rio de Janeiro: Vozes, 1994. p. 35-86.

LAZZARATO, M.; NEGRI, A. Trabalho imaterial: formas de vida e produção de subjetividade. Rio de Janeiro: DP\&A, 2001.

LAZZARATO, M. Trabalho e capital na produção dos conhecimentos: uma leitura através da obra de Gabriel Tarde. In: COCCO, G.; GALVÃO, A.P.; SILVA, G. (Org.). Capitalismo cognitivo: trabalho, redes e inovação. Rio de Janeiro: DP\&A, 2003. p. 61-82.

LAZZARATO, M. As revoluções do capitalismo. Rio de Janeiro: Civilização Brasileira, 2006.

MEISTER, J.C. Educação corporativa: a gestão do capital intelectual através das universidades corporativas. São Paulo: Pearson, 1999.

NARDI, H.C. Ética, trabalho e subjetividade: trajetórias de vida no contexto das transformações do capitalismo contemporâneo. Porto Alegre: UFRGS, 2006.

O PONTO de partida é você. Zero Hora, Porto Alegre, 6 abr. 2008. Caderno Empregos \& Oportunidades. Brasil, p. 2.

POR QUE devo contratar você? Zero Hora, Porto Alegre, 1 jun. 2008. Caderno Empregos \& Oportunidades. Brasil, p. 2.

QUALIFIQUE-SE e apareça. Zero Hora, Porto Alegre, 24 fev. 2008. Caderno Empregos \& Oportunidades. Brasil, p. 1.

SANDRONI, P. Novo Dicionário de Economia. 9. ed. São Paulo: Best Seller, 1999.

SARAIVA, K. Outros tempos, outros espaços: internet e educação. 2006. 275f. Tese (Doutorado em Educação) - Programa de Pós-Graduação em Educação, Faculdade de Educação, Universidade Federal do Rio Grande do Sul, Porto Alegre.

SENNETT, R. A corrosão do caráter: consequências pessoais do trabalho no novo capitalismo. 9. ed. Rio de Janeiro: Record, 2005.

SENNETT, R. A cultura do novo capitalismo. Rio de Janeiro: Record, 2006.

TAYLOR, F.W. Princípios da administração científica. São Paulo: Atlas, 1990.

VALORIZE sua habilidade. Zero Hora, Porto Alegre, 15 jun. 2008. Caderno Empregos \& Oportunidades. Brasil, p. 1. 
Capacitações perecíveis do trabalhador: a busca de saberes comportamentais...

VEIGA-NETO, A. Coisas do governo... In: RAGO, M.; ORLANDI, L.; VEIGA-NETO, A. (Org.). Imagens de Foucault e Deleuze: ressonâncias nietzschianas. Rio de Janeiro: DP\&A, 2002. p. 13-34.

VEIGA-NETO, A. Foucault e a educação. Belo Horizonte: Autêntica, 2003.

Recebido em 29 de maio de 2012.

Aprovado em 24 de maio de 2013. 